\title{
Some Simple Improvements to an Emergency Response Model for Use in Complex Coastal Terrain
}

by N.L. Miller

Environmental Research Division,

Argonire National Laboratory, 9700 South Cass Avenue, Argonne, Illinois 60439

June 1992

Work sponsored by United States Department of Energy,

Office of Energy Reseanch, Dffice of Health and Environmental Fesearch. 


\section{Contents}

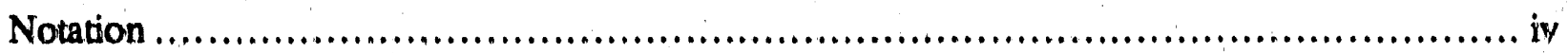

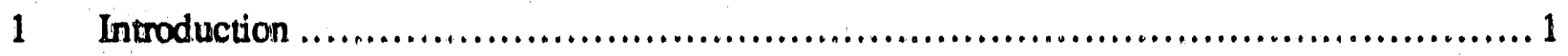

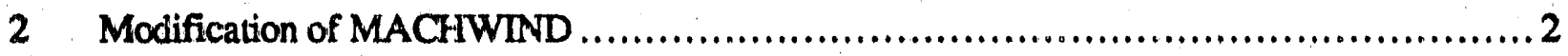

2.1 Sigma Heights.................................................................. 2

2.2 Modification for Vertically Extrapolated Wind Fields .............................. 3

2.3 Implementation of a Sea Breeze ................................................5

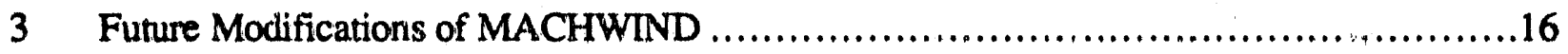

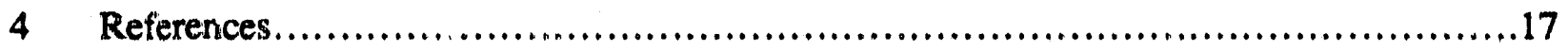

Appendix: Modifications to MACHWIND Code ..........................................19

\section{Figures}

1 Original Fixed Sigma Heights, Specified as 0.0, 3.66, 16.46, 31.09, 62.18, and $91.44 \mathrm{~m}$ above Surface Contours ................................................ 4

2 Computed Sigma Heights that Fit the Topography near the Surface

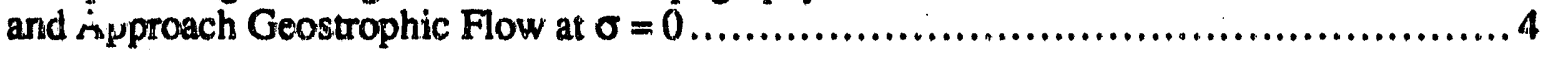

3 Tower Locations and Elevated Terrain in the Vicinity of Vandenberg Air Force Base........ 5

4 Schematic Diagram for Computation of the Average Wind Direction, $D_{\text {comp }} \ldots \ldots \ldots \ldots \ldots \ldots \ldots 6$

5 Wind Flow Fields over the Vandenberg Air Force Base Region hefore Modification of Unrepresentative Winds, for Sigma Levels

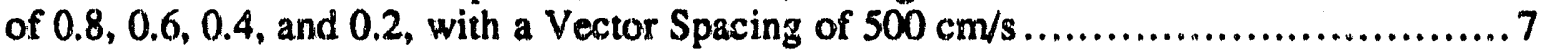

6 Wind Flow Fields over the Vandenberg Air Force Base Region after Wind Field Modification, for Sigma Levels of 0.8, 0.6, 0.4, and 0.2,

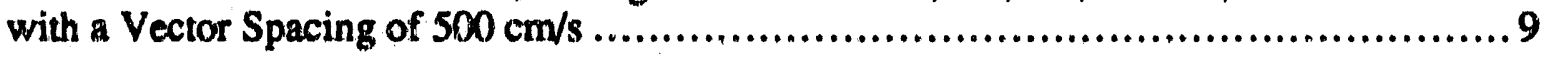

7 Schematic Diagram for Computing a Crude Sea Breeze for an Assumed North-South Coastine

8 Zonally Approximated Sea Breeze at Sigma Levels of 0.8, 0.6, 0.4, and 0.2, for a L and-Sea Temperature Difference of $5^{\circ} \mathrm{C}$, with a Vector Spacing of $500 \mathrm{~cm} / \mathrm{s} . \ldots \ldots \ldots 12$

9 Zonally Approximated Sea Breeze at Sigma Levels of 0.8, 0.6, 0.4, and 0.2, for a Land-Sea Temperature Difference of $20^{\circ} \mathrm{C}$, with a Vector Spacing of $500 \mathrm{~cm} / \mathrm{s}$ 


\section{Notation}

\begin{tabular}{|c|c|}
\hline$D_{j}$ & measured wind direction \\
\hline$D_{\text {comp }}$ & computed average wind direction \\
\hline g & gravitational constant \\
\hline $\mathrm{h}$ & height of layer \\
\hline L & horizontal distance between a tower and a location at sea \\
\hline $\mathrm{n}$ & number of meteorological towers \\
\hline $\mathbf{P}_{\mathbf{k}}$ & pressure at sigma level $k$ \\
\hline $\mathbf{P}_{\mathbf{S}}$ & pressure at surface \\
\hline $\mathbf{P}_{\mathbf{T}}$ & pressure at height of geostrophic flow \\
\hline $\mathbf{R}$ & universal gas constant for dry air \\
\hline $\mathbf{R}_{\mathbf{i}}$ & radial distance from tower $i$ to evaluated tower $j$ \\
\hline $\mathbf{R}_{\mathbf{s}}$ & sweep radius (radius of influence) \\
\hline$\overline{T_{j}}$ & average temperature at jth tower \\
\hline$\overline{\mathrm{T}}_{\mathbf{s e n}}$ & average temperature at sea \\
\hline$T_{\mathbf{k}}$ & temperature at sigma level $\mathrm{k}$ \\
\hline$U_{s}$ & time-dependent sea breeze \\
\hline VAFB & Vandenberg Air Force Base \\
\hline w & weighting factor that linearly increases $R_{S}$ with height \\
\hline$x_{i}, y_{i}$ & coordinates of meteorological towers other than tower $j$ \\
\hline$x_{j}, y_{j}$ & coordinates of meteorological tower $j$ \\
\hline $\mathbf{Z}_{\mathbf{k}}$ & geopotential height of sigma level $\mathrm{k}$ \\
\hline$\Delta t$ & time step \\
\hline$y_{k+1}$ & grid-point-dependent lapse rate at sigma level $k+1$ \\
\hline$\pi$ & $\mathbf{P}_{S}-\mathbf{P}_{\mathrm{T}}$ \\
\hline$\sigma$ & vertical modeling surface \\
\hline
\end{tabular}




\section{Some Simple Improvements \\ to an Emergency Response Model \\ for Use in Complex Coastal Terrain}

by

\section{N.L. Miller}

\section{Introduction}

The MACHWIND model (Meyers 1989) is one of a group of models used to cornpute regional wind fields from tower wind data and/or vertical wind profiles. The wind fields are in turn used to calculate atmospheric diffusion, to guide emergency responses. MACHWIND has performed acceptably in uniform terrain under steady, well mixed conditions. However, extension of the model to more complex situations is problematic. In coastal, hilly terrain like that near Vandenberg Air Force Base (VAFB) in southern California, calculations of the wind field can be enhanced significantly by several modifications to the original code. This report highlights the structure of MACHWIND and details the enhancements that were implemented.

The MACHWIND model uses available meteorological data and information on surface topography to produce an extrapolated wind field for calculations over a $100-\mathrm{km}$ by $100-\mathrm{km}$ domain of atmospheric diffusion during an emergency response. The terrain is described with a fine grid spacing of $1 \mathrm{~km}$ by $1 \mathrm{~km}$. A medium grid $(2 \mathrm{~km}$ by $2 \mathrm{~km})$ and a coarse grid ( $4 \mathrm{~km}$ by $4 \mathrm{~km}$ ) are derived from the fine grid spacing. In the present use, wind speed and direction are assumed to be provided by 24 towers clustered mainly along the western portion of VAFB, between the Pacific coast and the coastal mountain range. Of these 24 towers, 12 provide measurements of wind speed and direction $3.7 \mathrm{~m}$ above the surface, 10 provide measurements at two levels $(3.7$ and $16.5 \mathrm{~m}), 1$ has four measurement levels $(3.7,16.5,31.1$, and $62.1 \mathrm{~m})$, and 1 has five measurement levels $(3.7,16.5,31.1,62.1$, and $91.4 \mathrm{~m})$.

To provide data for MACHWIND, wind speed and direction are extrapolated to fit a logarithmic profile asymptotic to geostrophic flow above each tower. Fixed heights $(3.7,16.5$, $31.1,62.2$, and $91.4 \mathrm{~m}$ ) are specified to match tower measurements. Missing data for wind speed and direction are extrapolated to each level for each tower. MACHWIND computes a wind field for each grid point at each level by using inverse-squared distance weighting of the tower wind data extrapolated to the grid point at each height. From this data set, wind fields for coarse, medium, and fine grids are calculated to achieve an iterative fit with data for the fixed heights. 


\section{Modification of MACHWIND}

MACHWIND as it is currently designed computes the wind field with several significant restrictions. The improvements suggested here involve (1) definition of hei ghts, (2) vertical extrapolation of winds, and (3) implementation of a very simple first approximation to a sea breeze. Although they are incomplete, these initial modifications to MACHWIND should improve extrapolation of wind fields in a mountainous coastal region so that an eniergency response can be more properly implemented.

\subsection{Slgma Heights}

The original MACHWIND model describes the vertical grid spacing in terms of fixed height intervals above local terrain (Figure 1). Fixed heights may be acceptable over flat terrain, but the specified heights do not exceed $100 \mathrm{~m}$, and the application here is over complex terrain. The height specification also presents problems because of (1) the nonconservation of mass in each layer and (2) diffusing plumes whose depth significantly exceeds $100 \mathrm{~m}$.

These problems can be avoided if the vertical levels are defined with sigma surfaces (Phillips 1957) so that the top level coincides with the geostrophic flow. Each sigma level is described here as

$$
\sigma_{k}=\left(P_{k}-P_{T}\right) / \pi
$$

where $P_{k}$ is the pressure at the current height, $P_{T}$ is the pressure at the height of geostrophic flow, and $\pi=P_{S}-P_{T}$ is the difference between the surface pressure, $P_{S}$, and $P_{T}$. The value of $P_{T}$ for observed geostrophic flow will vary, but it can be determined from local rawinsonde measurements.

The surface pressure at each grid point is computed from a given local sea level pressure by assuming that dry adiabatic conditions prevail from sea level to the height of the local terrain. The geopotential heights of the sigma levels are computed as

$$
Z_{k}=Z_{k+1}-R T_{i} / g\left(d \ln P_{k}\right) /\left[1-(R / g)\left(\gamma_{k+1} / 2\right) d \ln P_{k}\right],
$$

where

$$
\mathrm{d} \ln \mathrm{P}_{\mathrm{k}}=\pi\left(\sigma_{\mathrm{k}}-\sigma_{\mathrm{k}+1}\right) /\left(\mathrm{P}_{\mathrm{T}}-\pi \sigma_{\mathrm{k}+1}\right) .
$$

in Equation 2, $\mathbb{R}$ is the universal gas constant for dry air, $T_{k}$ is the temperature at sigma level $k, g$ is the gravitational constant, and $\gamma_{k+1}$ is the grid-point-dependent lapse rate at level $k+1$. The value of $k$ ranges from 1 to 6 , where the top level $(\sigma=0.0)$ is 1 , the surface level $(\sigma=1.0)$ is 6 , and $\mathrm{k}+1$ is the next level downward, toward the surface. When they are implemented, sigma levels at $0.92,0.94,0.96$, and 0.98 will allow analysis in niner detail of the flow behavior near the surface. This modification is based on the hydrostatic approximation and is formulated as 
subroutine RELHT, called by subroutine TOPO from within the program MACHWIND (see Appendix).

Figures 1 and 2 show the wind field heights before and after the implementation of proper sigma levels. The surface contour represents a west-to-east cross section across VAFB and the adjacent regions. This change in heights is clearly necessary to conserve mass and is thus desirable for diffusion modeling.

\subsection{Modification for Vertically Extrapolated Wind Fields}

Low-level winds over VAFB are computed from 24 towers, which are mainly clustered about the western portion of the emergency response region (Figure 3). In this region, the Pacific Ocean lies to the immediate west and south; coastal ranges with surface heights over $300 \mathrm{~m}$ are oriented northwest to southeast. Approximately $30-40 \mathrm{~km}$ inland, the Pacific Crest range covers the eastern region, with surface elevations over $420 \mathrm{~m}$.

Logarithmic profiles between the surface and the geopotential flow (assumed to be $1,000 \mathrm{~m}$ ) are fitted to available tower data and then interpolated to each height level, but wind direction is initially held constant with height. The implemented modification searches for outliers at heights above the towers; uncharacteristic flow is then recalculated as shown below. This modification will tend to bring the winds into alignment with the geostrophic flow as the sigma surfaces approach the height of geostrophic flow. At each tower location, a weighted average velocity is computed. This height-dependent velocity is determined by computing a sweep radius as follows:

$$
R_{S}=w / n \sum_{i=1 ; i \neq j}^{n} \sqrt{\left(x_{j}-x_{i}\right)^{2}+\left(y_{j}-y_{i}\right)^{2}} .
$$

Here $w$ is a weighting factor that linearly increases the sweep radius with height, $\mathrm{n}$ is the number of meteorological towers, $x_{j}$ and $y_{j}$ are the coordinates of the tower being evaluated, and $x_{i}$ and $y_{i}$ are the coordinate locations of each of the remaining towers.

The sweep radius $R_{S}$ represents a radius of influence and allows for analysis of the wind at the jth tower, exclusive of data from that tower (Figure 4). The distance between the ith tower and the evaluated tower $j$ is denoted as $R_{i}$. Comparison of the measured wind direction and the computed wind direction at the jth tower determines whether any smoothing is required. If the absolute value of the difference between the measured wind direction $\left(D_{j}\right)$ and the computed average wind direction $\left(D_{\text {comp }}\right)$ is greater than $\varepsilon=D_{j} / 3$, then the actual wind field at the jth tower is replaced by the computed average. The computed wind direction is defined as

$$
D_{\text {comp }}=1 / n \sum_{i=1}^{n} D_{i}\left(R_{i}<R_{s}\right)
$$




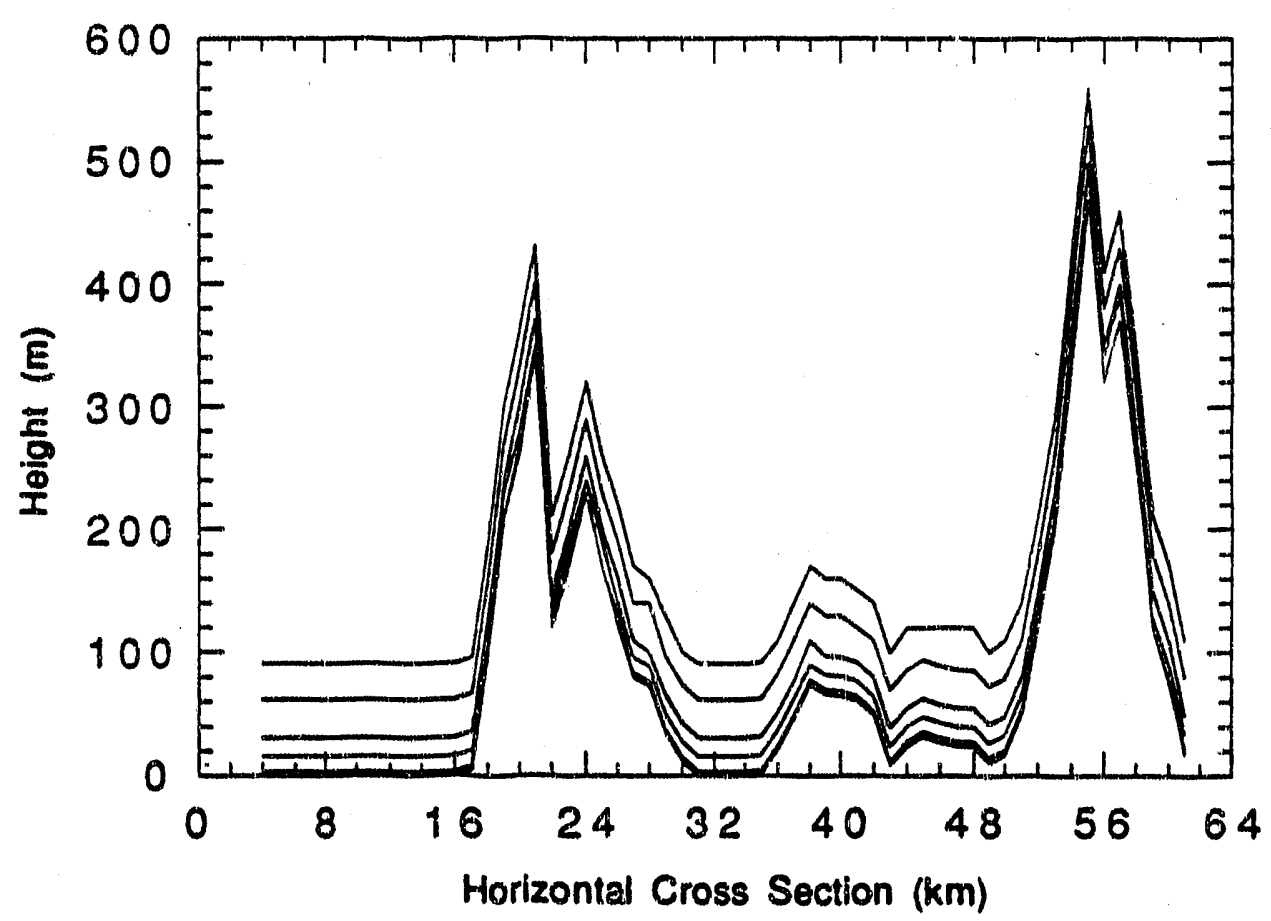

FIGURE 1 Original Fixed Sigma Heights, Specified as $0.0,3.66,16.46$, 31.09, 62.18, and $91.44 \mathrm{~m}$ above Surface Contours

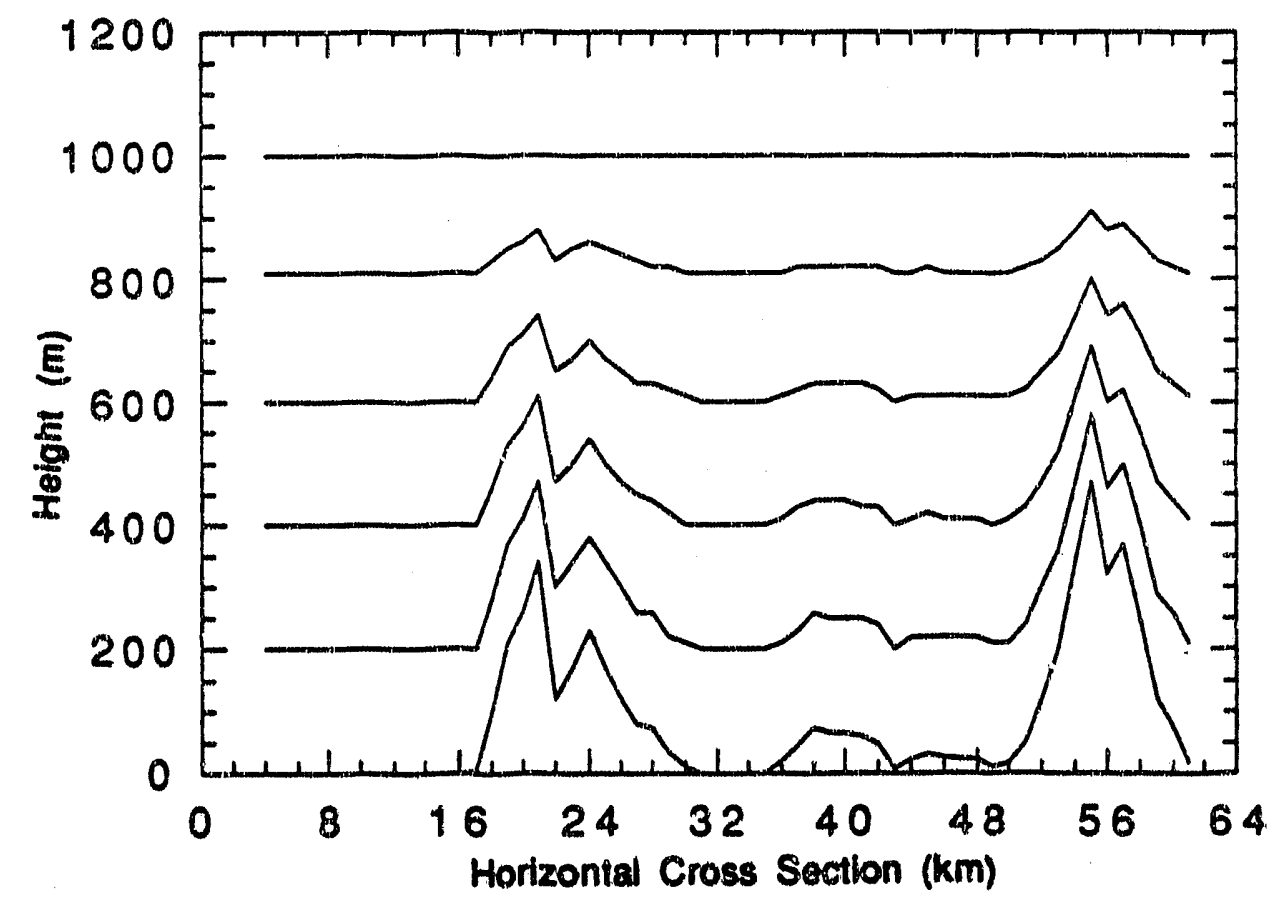

FIGURE 2 Computed Sigma Heights that Fit the Topography near the Surface and Approach (Seostrophic Flow at $\sigma=0$ 


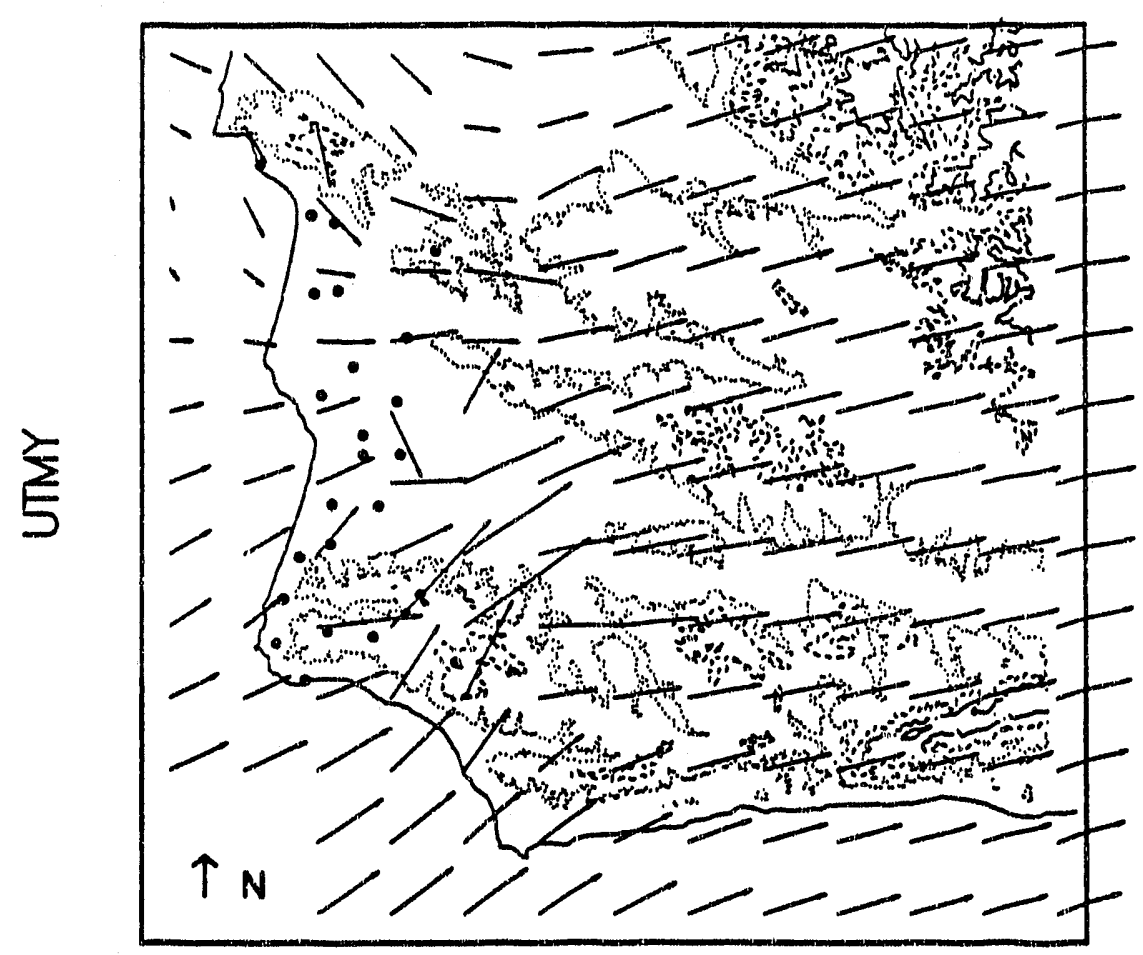

UTMX

FIGURE 3 Tower Locations (closed circles) and Elevated Terrain (contours) in the Vicinity of Vandenberg Air Force Base (Vectors represent wind speeds at sigma level 0.4.)

$$
\left|\left(D_{j}-D_{\text {comp }}\right)\right|>\varepsilon,
$$

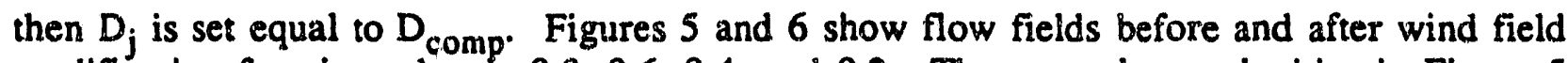
modification for sigma levels $0.8,0.6,0.4$, and 0.2 . The anomalous velocities in Figure 5 (circled) have been reanalyzed and replaced in Figure 6 . This modification is located in subroutine DOPSIG and is called subroutine WDTST (see Appendix).

\subsection{Implementation of a Sea Breeze}

Vandenberg Air Force Base is located along the California coast north of Los Angeles. The diumal variations in the wind field due to the losal sea breeze must be accounted for if MACHWIND is to adequately predict the wind field over the region. Because MACHWIND is designed to extrapolate the winds for a fixed time, no mechanism is available to compute the onset and magnitude of the sea breeze. This restriction limits MACHWIND's ability to realistically 


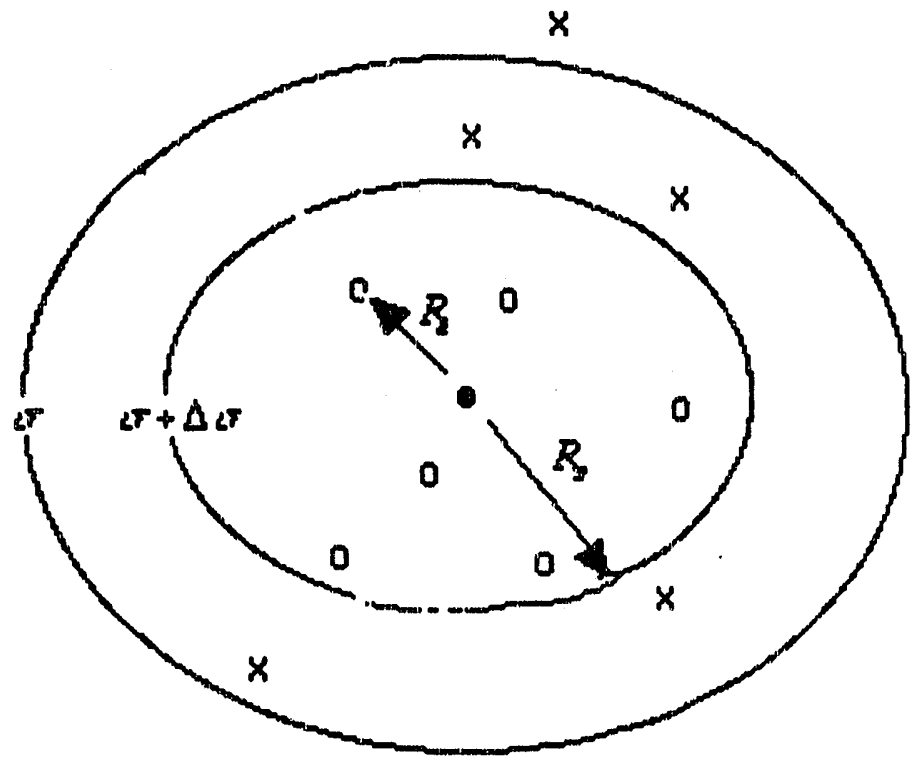

$\begin{array}{ll}- & \text { Tower being evaluated } \\ - & \text { Towers inside } R_{s} \text { used in the computed average } \\ \times & \text { Towers outside } R_{S_{s}} \text { not used in the computed average } \\ R_{8} & \text { Computed radius of influence } \\ R_{i} & \text {. Distance of tower } i \text { from evaluated tower } j \\ \sigma+\Delta \sigma & \text { Sigma level being evaluated } \\ \sigma & \text { Next sigma level above the } \sigma+\Delta \sigma \text { level }\end{array}$

FIGURE 4 Schematic Diagram for Computation of the Average Wind Direction, $D_{\text {comp }}$ (The inner large circle represents the mean tower distance at level $\sigma+\Delta \sigma$. Towers inside $R_{S}$ [small circles] were used to compute $D_{\text {comp.) }}$

simulate any time-dependent processes. Even with frequent updating, this wind field model is hampered by insufficient forcing.

To address this problem, a simple zonal sea breeze based on observed temperature has been incorporated into MACHWIND. This first approximation of the sea breeze is based on the vertical pressure difference $\left(P_{s}-P_{k}\right)$ at each tower and the average horizontal temperature difference between a column at the observation tower and a column at a location at sea that is equidistant from the shoreline. Because most of the coastline near VAFB is oriented north-south, a gross assumption of a sea breeze from the west is made here. This time-dependent sea breeze $\left(U_{s}\right)$ is defined as an add-on term to the west-to-east wind field and is defined as

$$
U_{s}=R \ln \left(P_{T} / P_{s}\right)\left(\bar{T}_{j}-\bar{T}_{\text {sea }}\right) /[2(h+L)] \Delta t .
$$



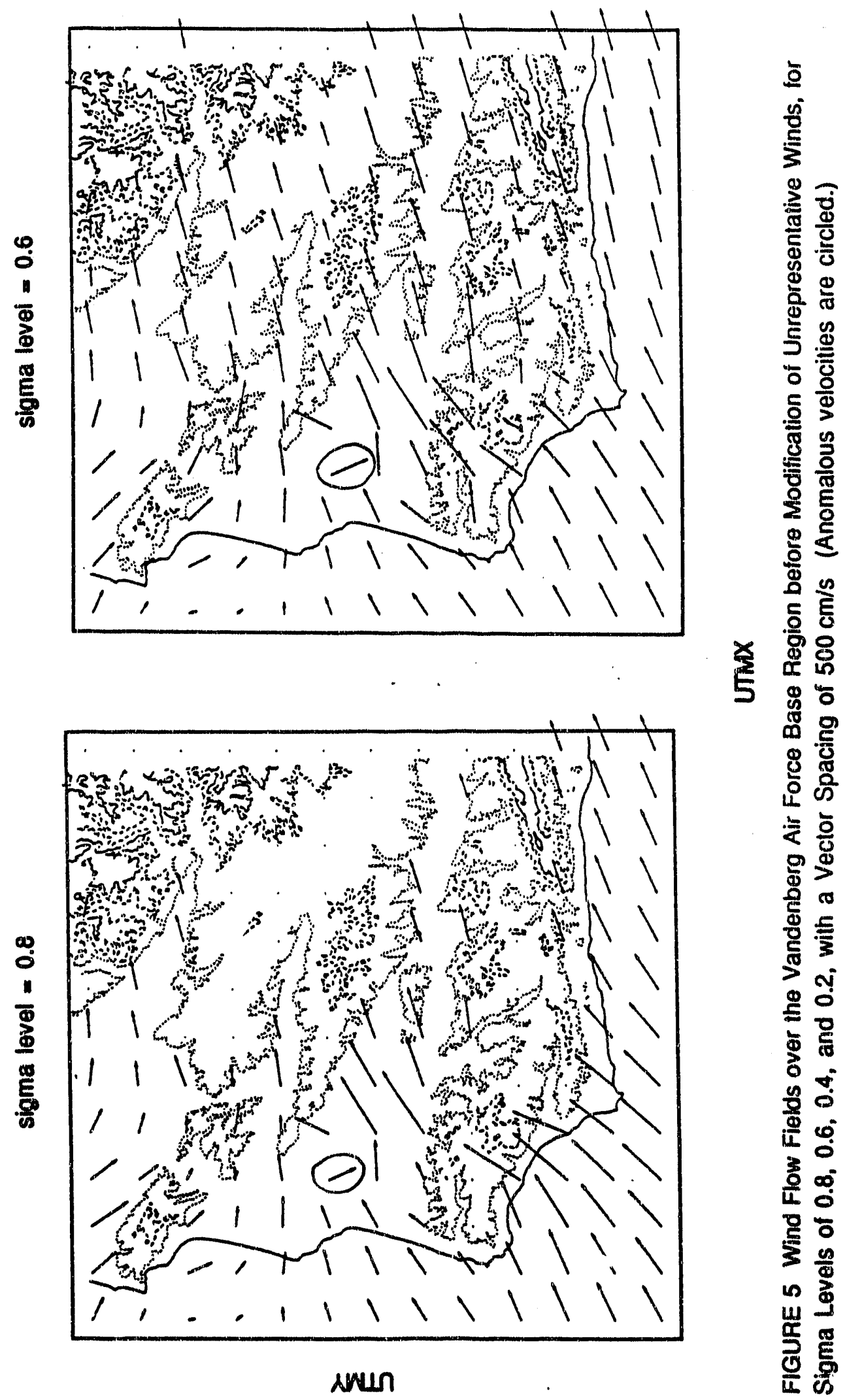

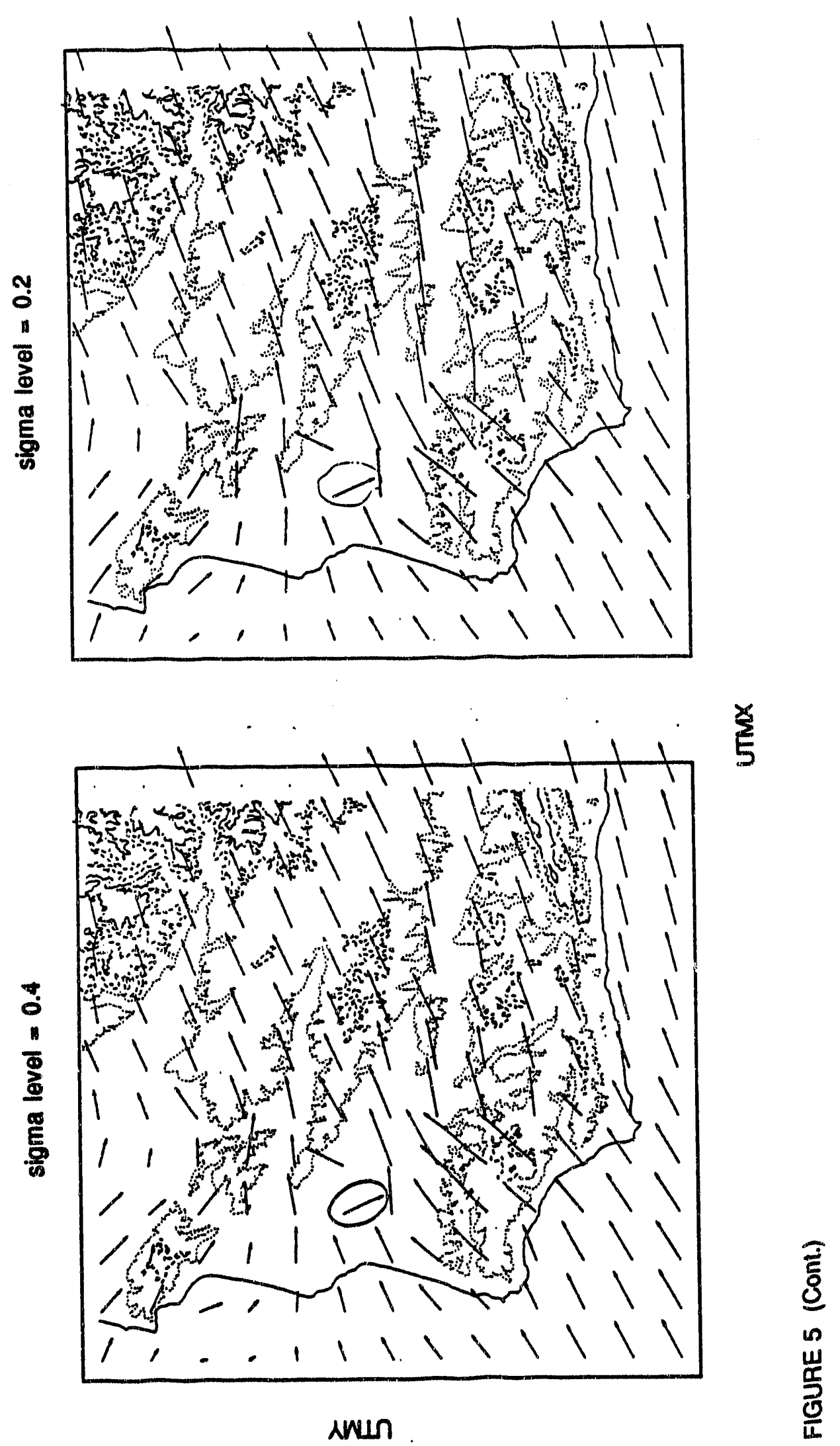

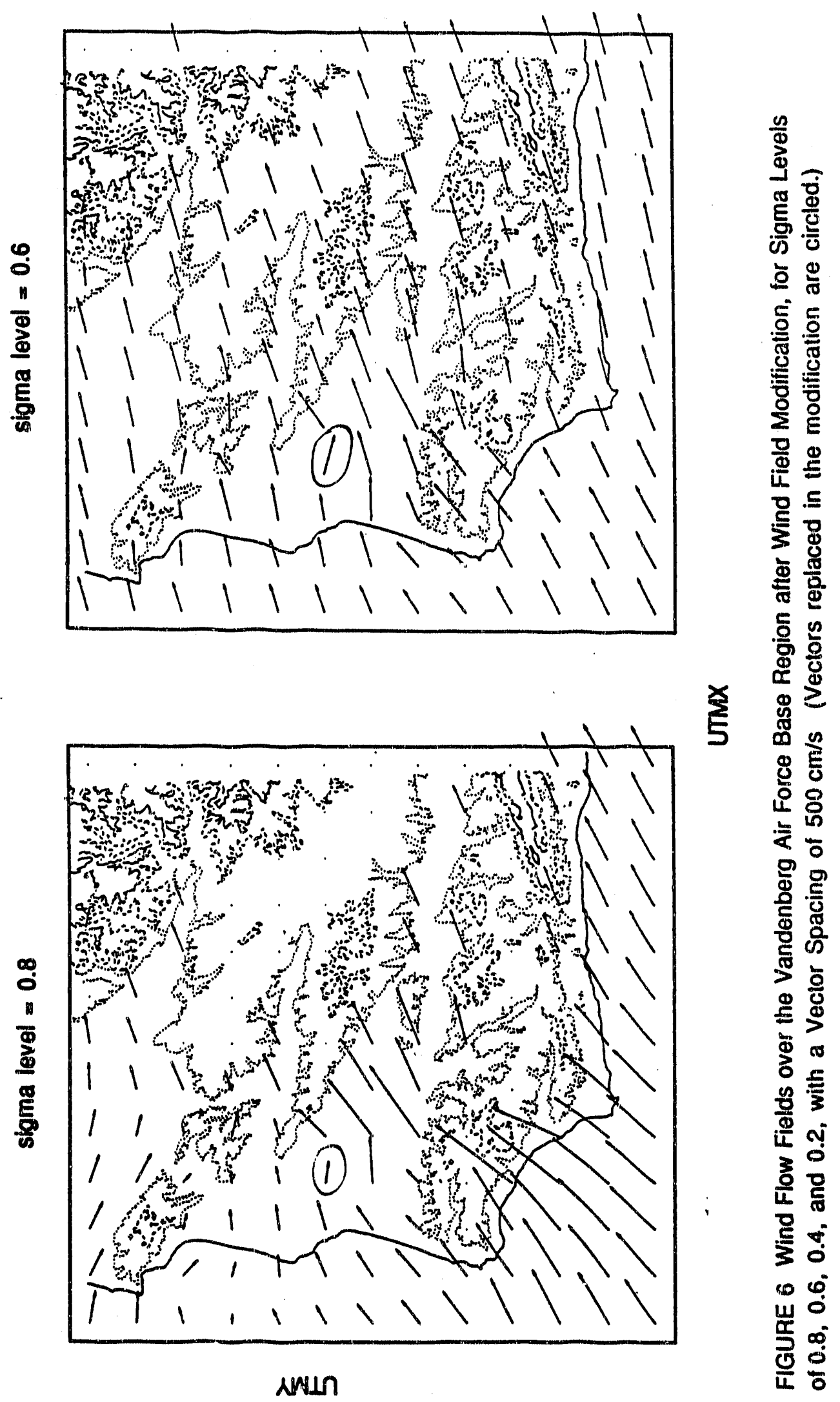

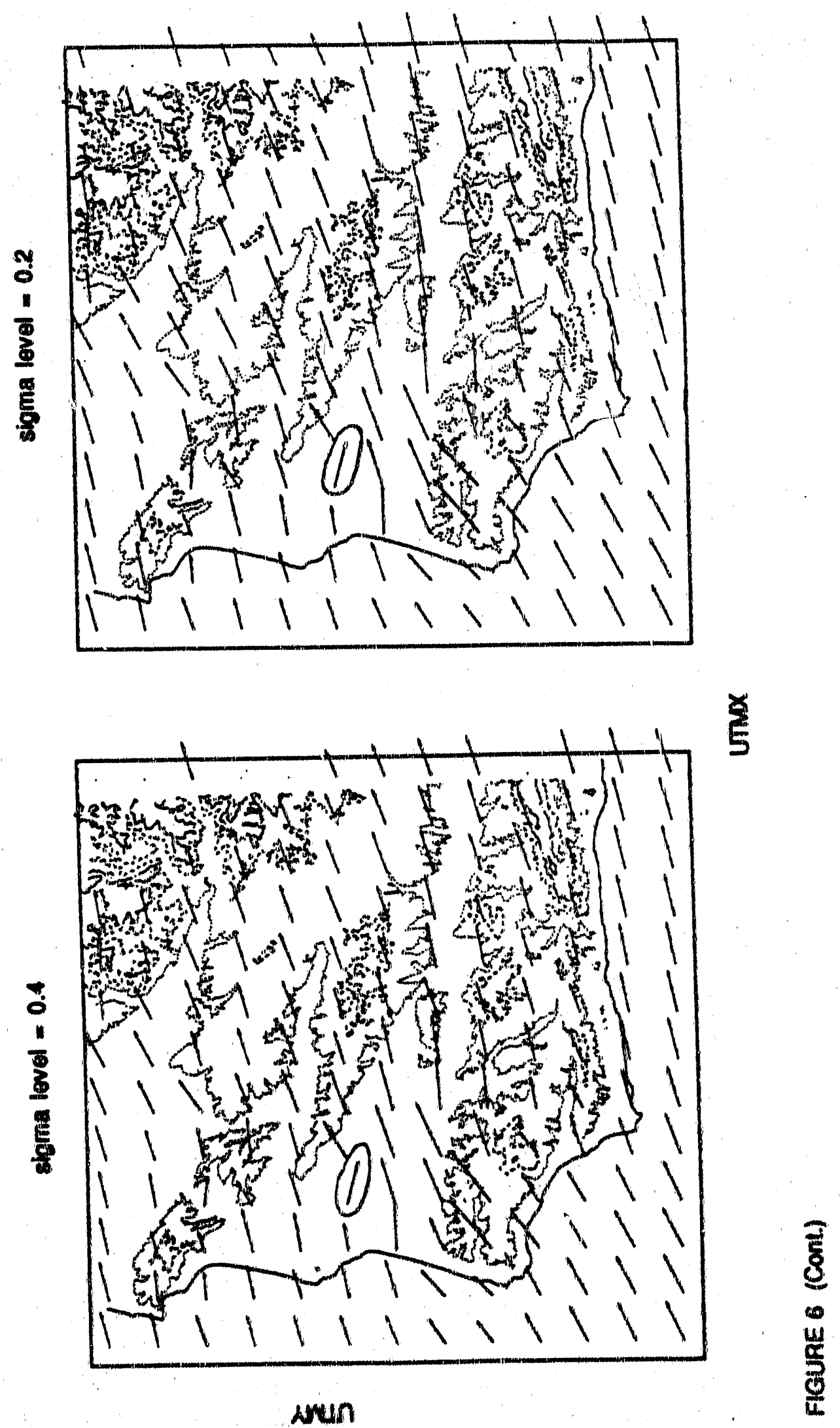
In Equation $7, \bar{T}_{j}$ and $\overline{\mathrm{T}}_{\text {sea }}$ are the average temperatures at the jth tower and at an adjacent sea location in a vertical column beiween $P_{S}$ and $P_{k}$ (at the jth tower). In addition, $L$ is the hurizontal displacement between the jth tower and the sea location, $h$ is the layer height, and $\Delta t$ denotes the time step. A schematic diagram of the sea breeze is shown in Figure 7.

The intensity of the sea breeze is illustrated in Figures 8 and 9 for initial land-sea surface temperature differences of $5^{\circ} \mathrm{C}$ and $20^{\circ} \mathrm{C}$, respectively. The tendency toward zonal flow in the presence of a sea breeze is most apparent as the land-sea temperature difference increases.

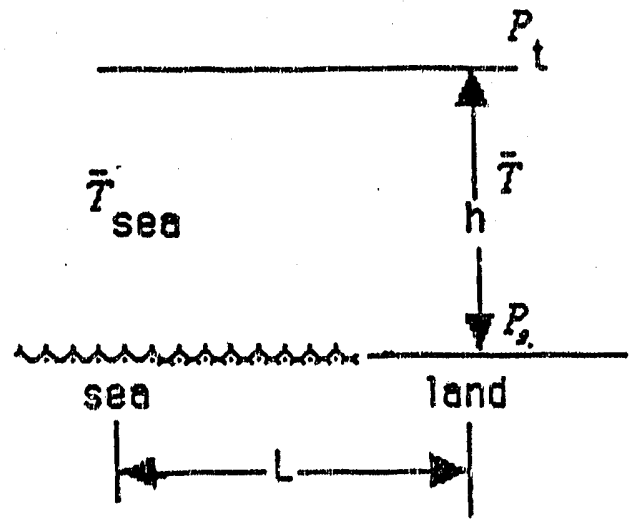

FIGURE 7 Schematic Diagram for Compuising a Crude Sea Breeze for an Assumed North-South Coastline 


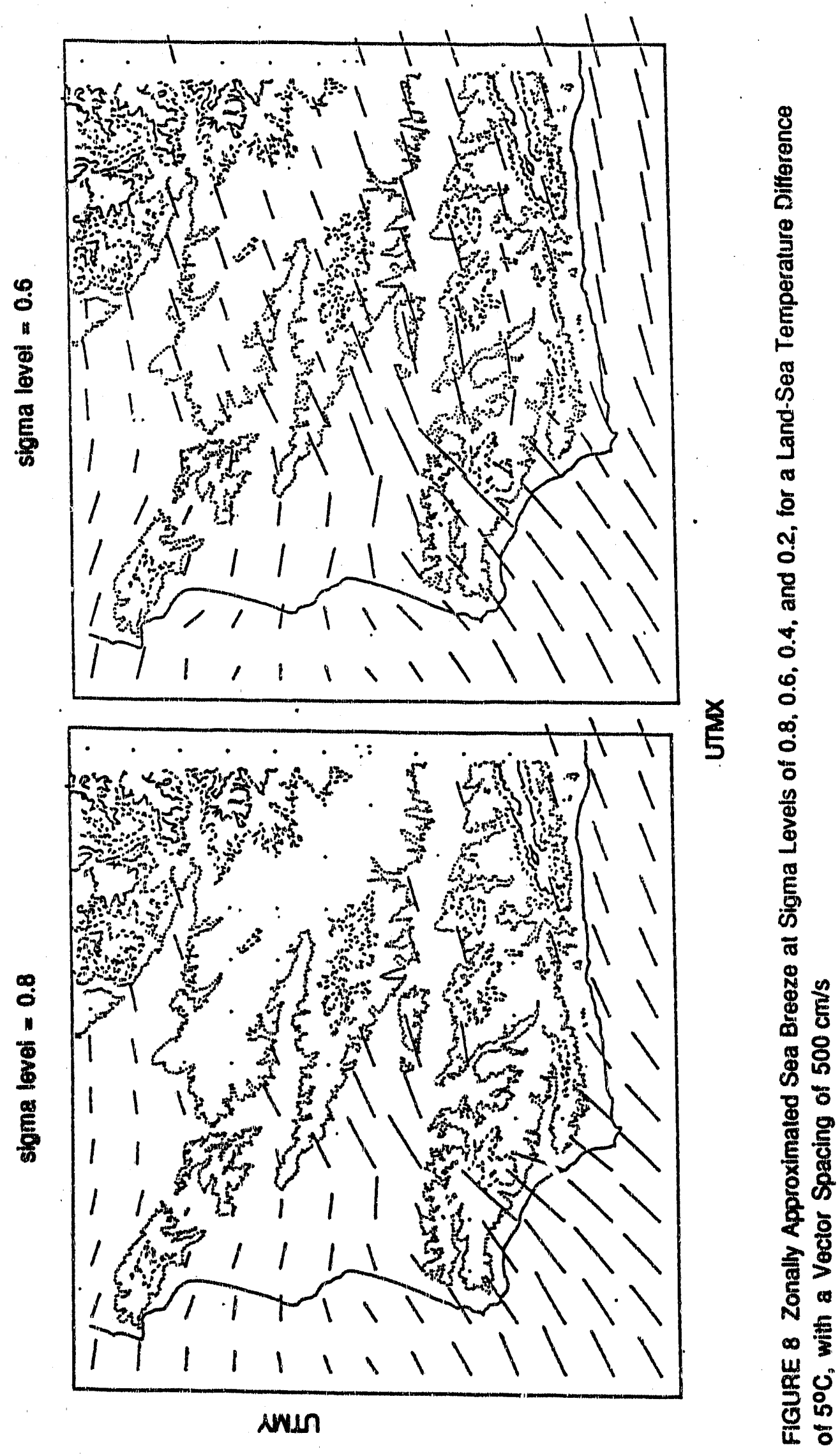



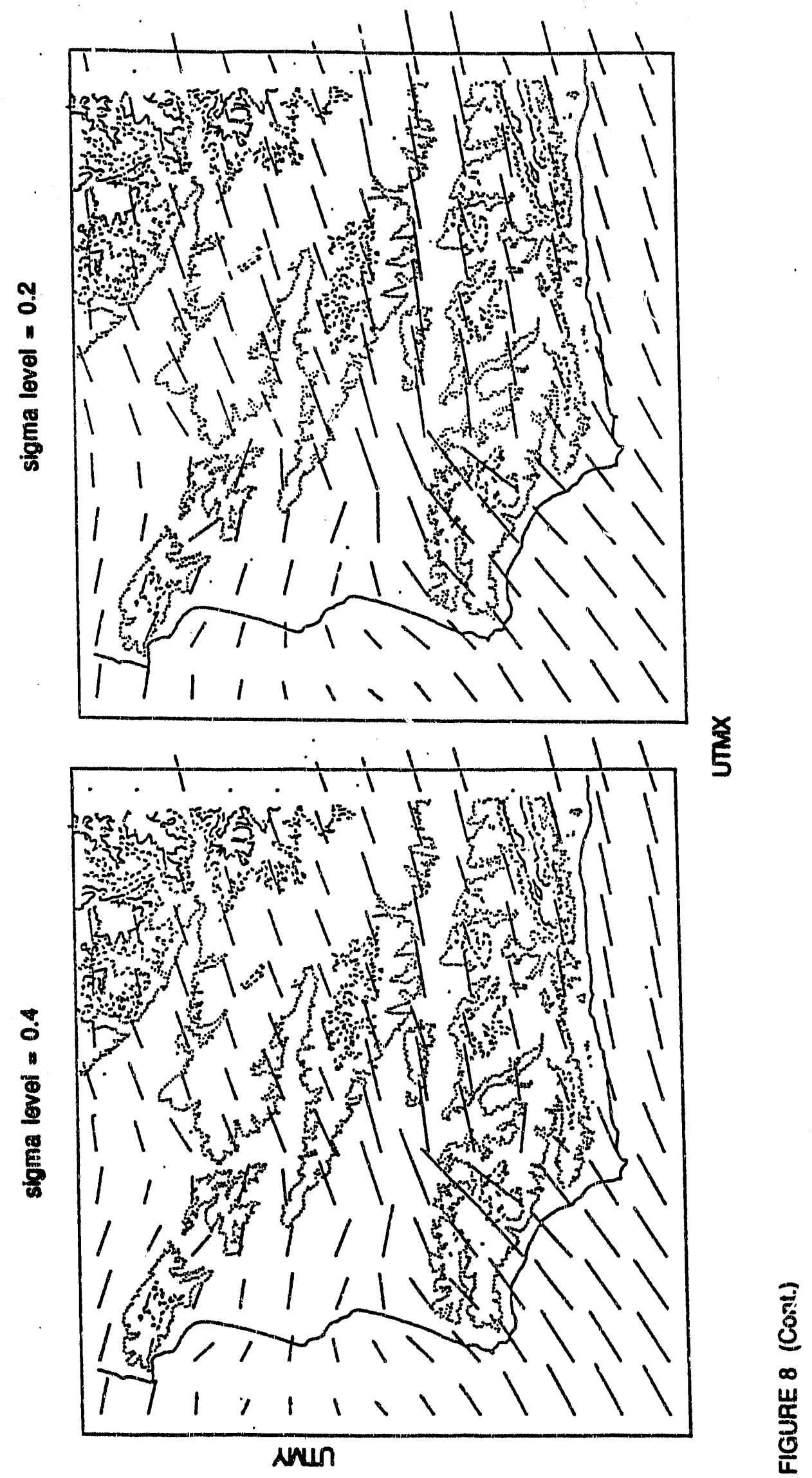

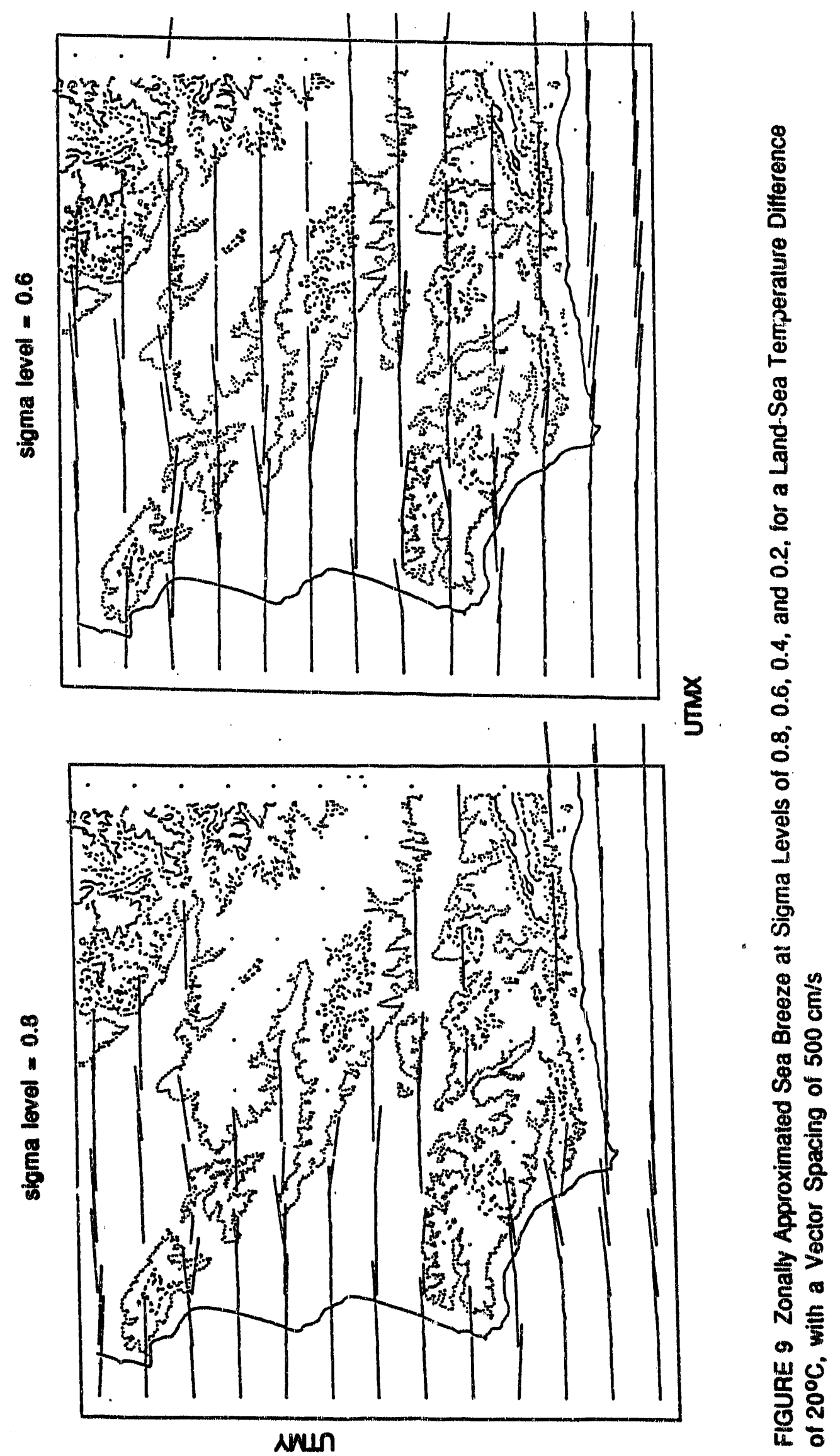

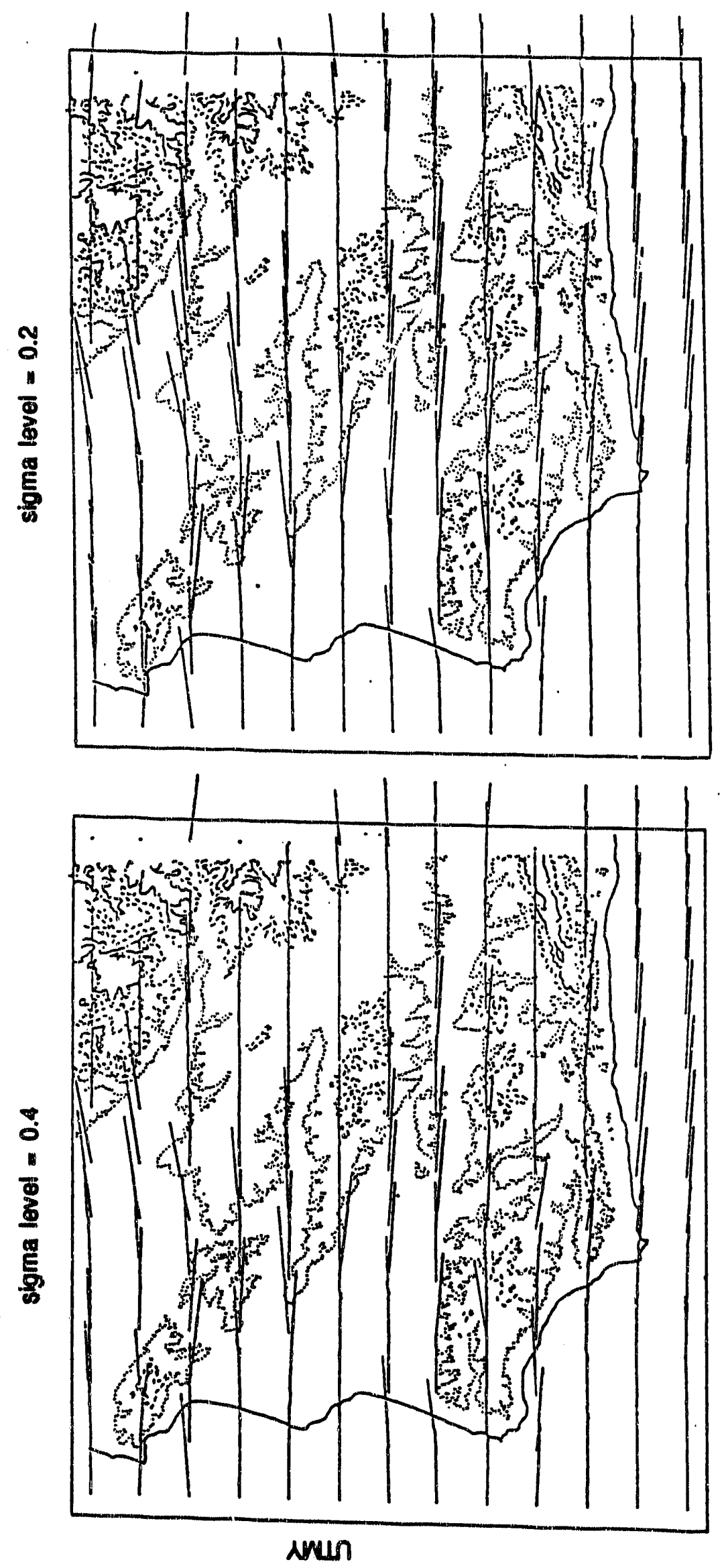

压

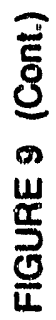




\section{Future Modifications of MACHWIND}

Further modifications of MACHWIND should include a more elaborate scheme for adjusting the vertically extrapolated velocity fields. Development of a code to incorporate (1) wind field adjustments based on topographic features and (2) regional averaging at each surface grid point will enhance the accuracy. Implementation of finer sigma levels near the surface will improve calculations of low-level diffusion. Because MACHWIND is a snapshot calculation (in a single time step), nesting this model in a time-dependent mesoscale scheme will allow calculation of time-dependent forcing and of growth processes in the boundary layer. For application to VAFB, more towers or other wind data are desirable, especially in the central and eastern mountainous areas. Coupling to the National Meteorological Center data to obtain information about geostrophic flow will also enhance this modil. 


\section{References}

Meyers, R.E., 1989, Preliminary Documentation of MACHWIND, U.S. Army Atmospheric Sciences Laboratory, White Sands Missile Range, N.M.

Phillips, N.A., 1957, "A Coordinate System Having Some s"secial Advantages for Numerical Forecasting," Journal of Meteorology, 14:184-185. 
$=$

$\underline{\underline{\underline{\underline{E}}}}$ 


\section{Appendix:}

\section{Modifications to MACHWIND Code}




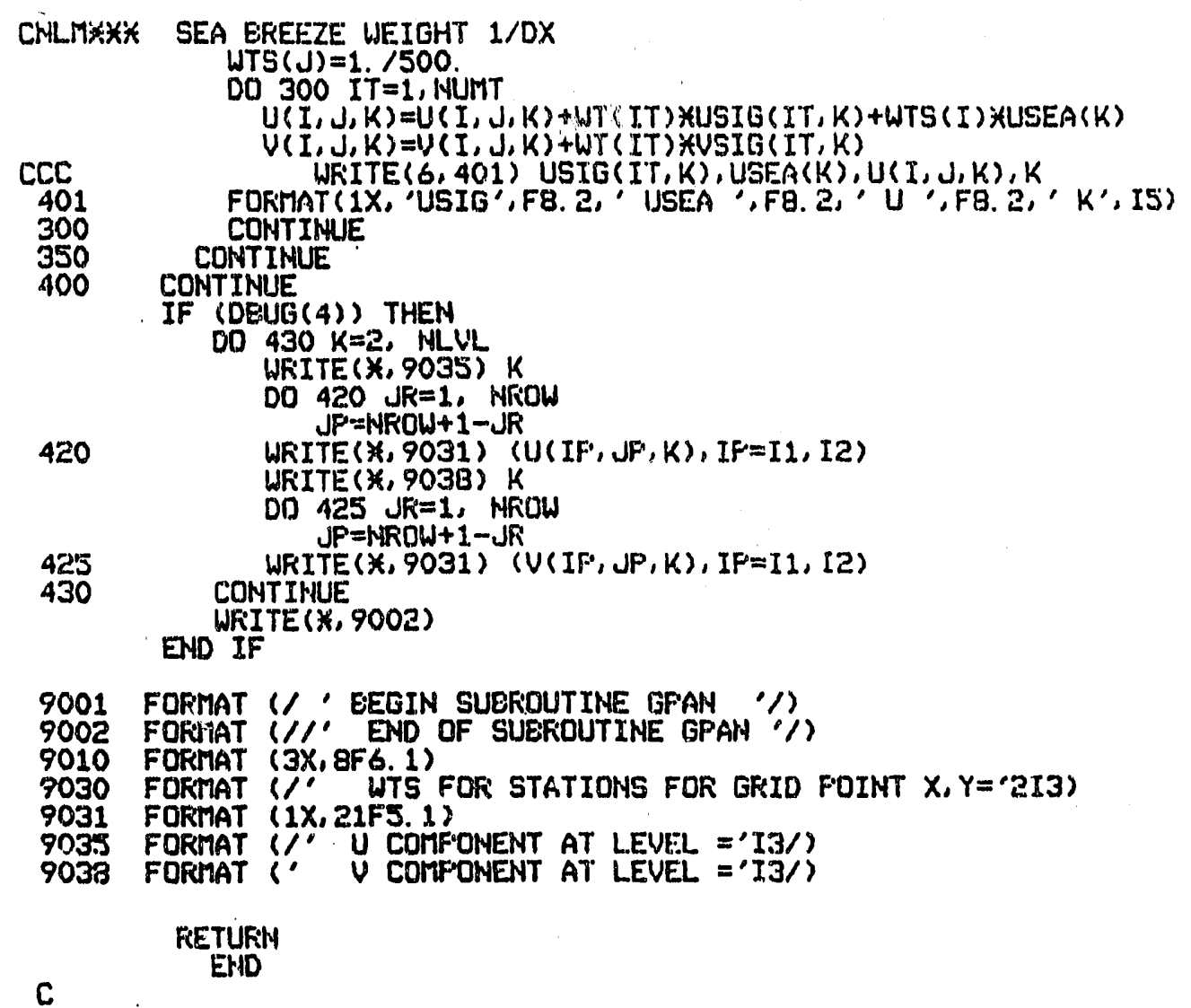




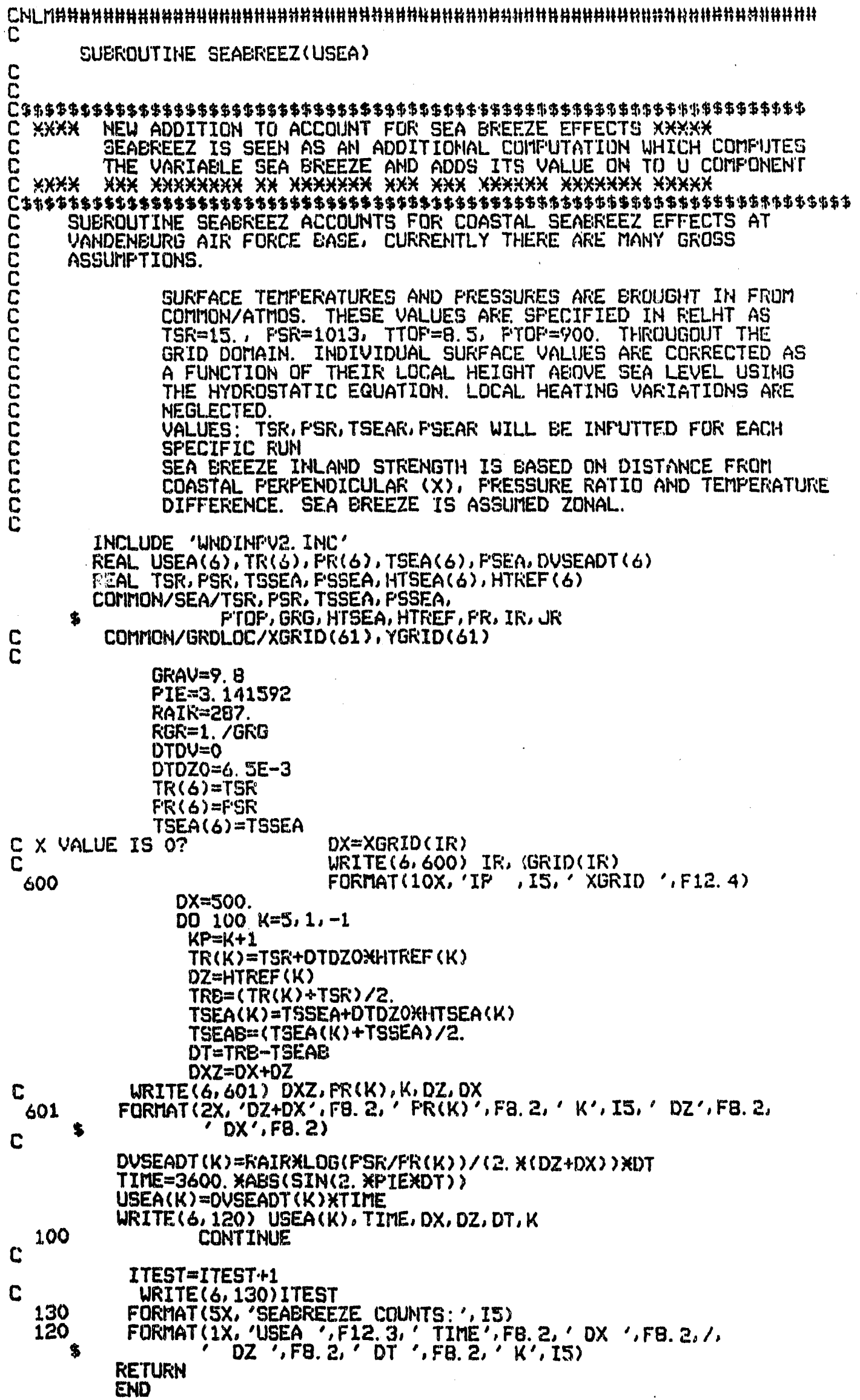


C 450 CONTINUE

IF(DEUG(2)) WRITE( $*, 9020)$ IT

IF (DEUG (2)) WRITE ( $*, 9010)$ (USIG $(I T, K), \operatorname{USIG(IT,K),K=1,HLVL)}$

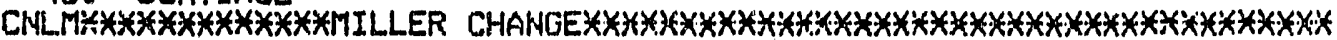

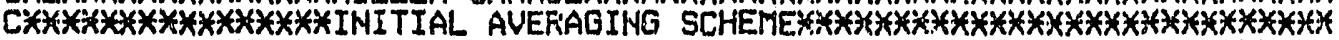

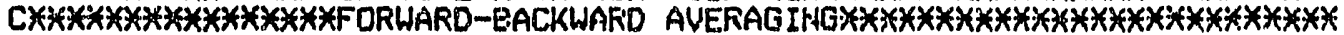

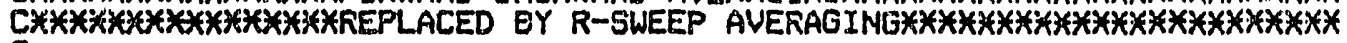
C

C USING UANDENEURG VALUES USIG, USIG COMPUTE WIND DIRECTION AND

C COMPARE TO MEIGHEORS, IF GREATER THAN 33\% THEN USE AUE VALUE

C FOR WIND DIRECTION, DECOMPOSE NEW USIG, USIG FFYN WOIR.

C.

ISKIF $=1$ (ISKIP. EQ. 1) GO TO 1177

DO $1455 \mathrm{~K}=2$, NLUL

001456 IT $=1,24$

IF (IT. EQ. 1) THEN

$I T M=2$

ITP $=I T+1$

ENDIF

IF (IT. EQ. NUMDOP) THEN

$I T M=I T-1$

ITP=NUMDOP -1

ENDIF

IF ( (IT. GT. 1). AND. (IT. LT. NUMDOF) ) THEN

$I T M=I T-1$

$I T P=I T+1$

ENDIF

C WRITE $(6,888)$ USIG(ITM, K), USIG (ITP, K), IT

C 888 FORMAT(2X, 'U(ITH)',FB. 2,' U(ITF)',Fg. 2,' IT', I4)

WDIR (ITM, K)=ATAN(USIG(ITM, K)/USIG $(I T M, K)$ )

WDIR $(I T P, K)=A T A N(U S I G(I T P, K) / U S I G(I T P, K)$ )

WDIR $(I T, K)=A T A N(U S I C I(I T, K) / U S I G(I T, K)$ )

WDAVE $=($ WDIK $(I T M, K)+W D I R(I T F, K)) / 2$.

UAVE $=(U S I G(I T M, K)+U S I G(I T F, K)) / 2$.

VAVE $=($ USIG $(I T M, K)+$ USIG $(I T F, K)) / 2$.

WDTST $=A E S$ ( (WDIR( IT, $K$ ) -WDAVE) /WDAUE)

IF (WOTST. GT. 0. 33) THEN

USIG $(I T, K)=$ LIAVE

USIG (IT,K) = VAVE

ENIDIF

C

WRITE $(6,1779)$ USIG (IT,K), USIG (IT,K), IT,K

1779

1.456

1455

1177 CONTINUE

CONT IKUUE

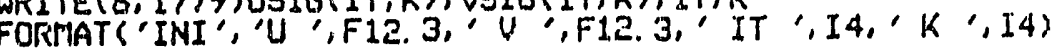

CONTINUE

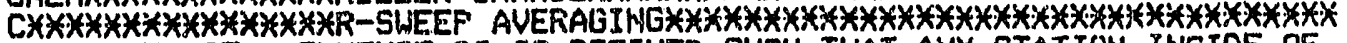

C RADIUS OF INFLUENCE RI IS DEFIHED SUCH THAT ANY STATION INSIDE OF

C A CINCLE MADE EY RI IS NOW INCDFFORPORATED INTO AN AVERAGING SCHEME

C WNDIR $=$ WWDIR $(I)+\operatorname{SUITCWNDIR}(J) / R(J) \times X 2$

C USINYG UAMDENEURG UALUES USIG, USTG COMPUTE WIMD DIRECTION AHD

C FDR WIND DIRECTIOH, DECOMPOSE HEW USIG, USIG FROH WDIR. 


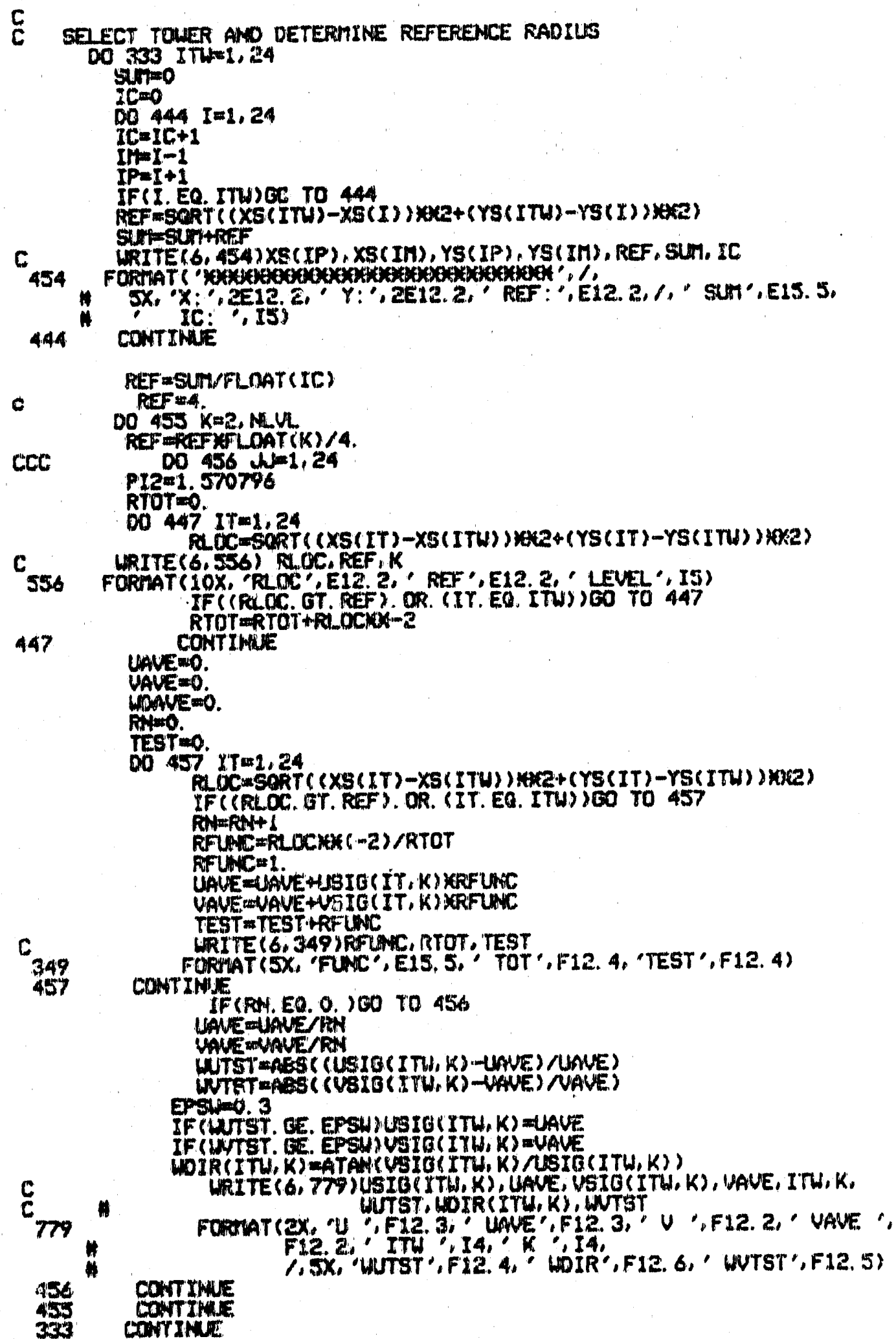




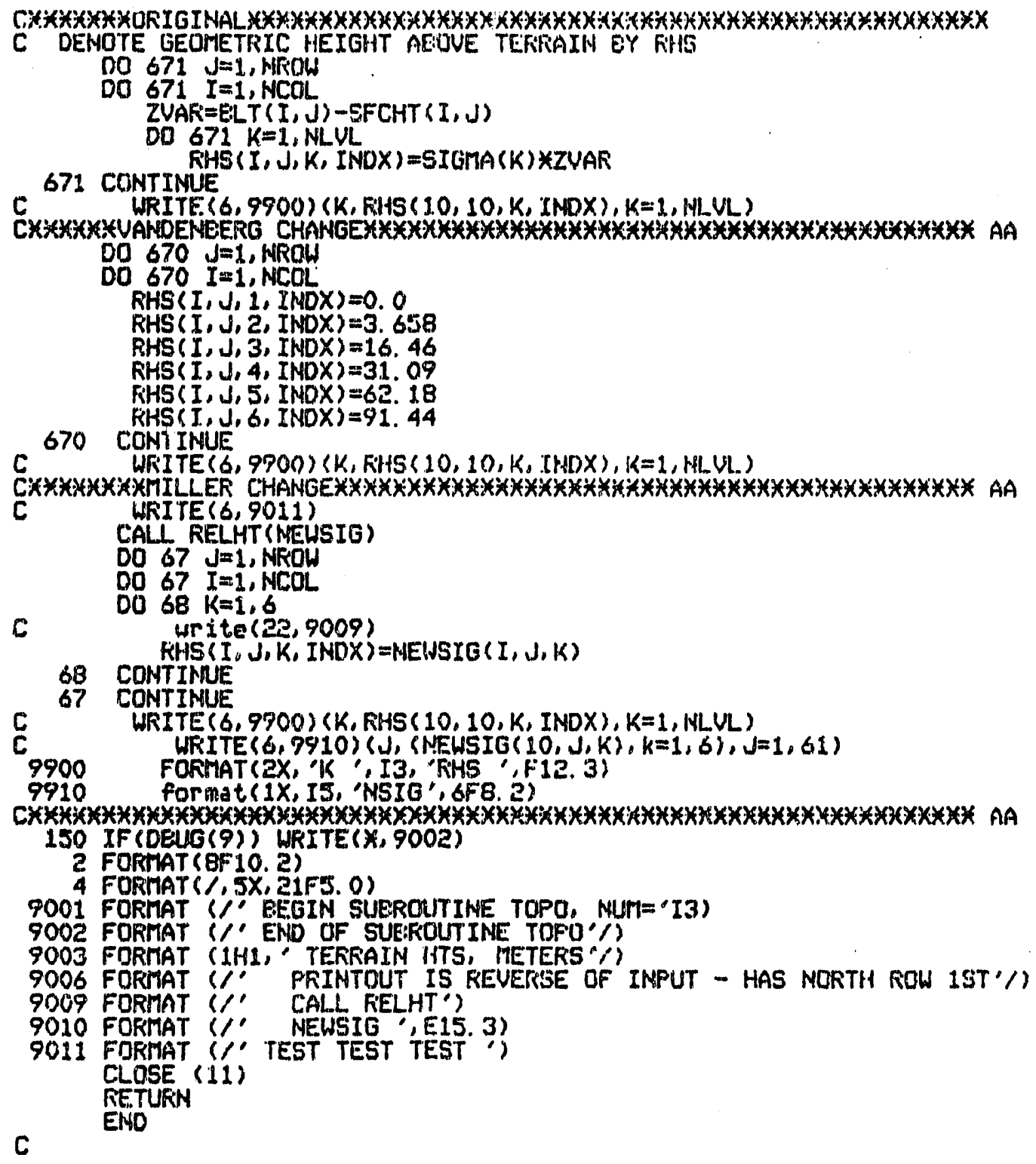




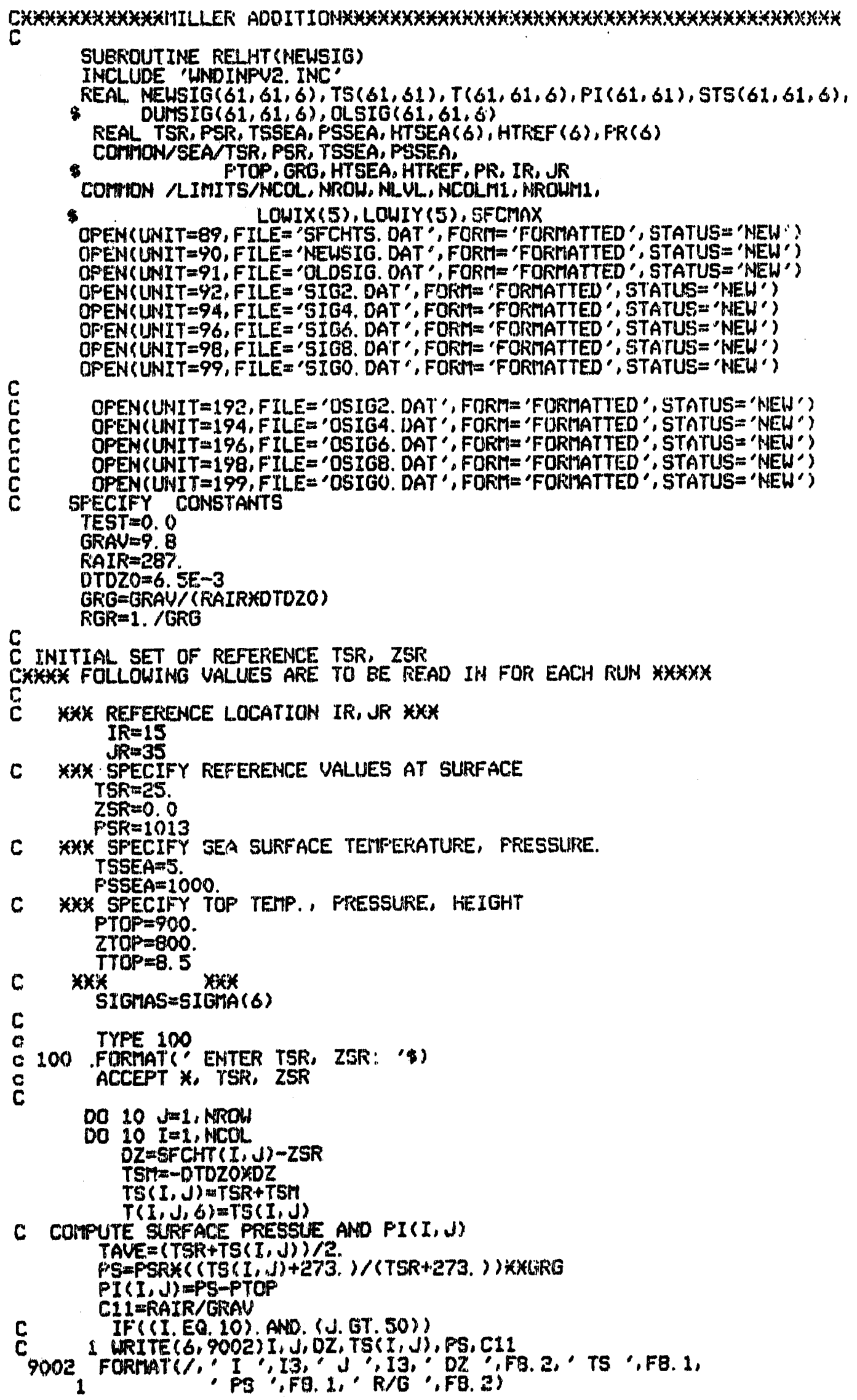


C COMFUTE GEOMETRTC SIGMA HEIGHTS

$\operatorname{MEWSIG}(I, J, 6)=\operatorname{SFCHT}(I, J)$

DO $11 K=5,1,-1$

$K F=K+1$

$D Z T=Z T O P-D Z$

C TEMP CHANGE

DTDZ $=-(\operatorname{TTOP}-T S(I, J)) / D Z T$

DTDZ =DTD7.0

$P I S=(P T O P+P I(I, J) * S I G M A(K)) /\left(P T O P+P I(I, J) * S I G M A\left(K F^{\prime}\right)\right)$

$Z S T E F=(T(I, J, K P)+273) *(1,0-($ FIS $) *$ *

STS $(I, J, K)=Z S T E P$

NEWSIG $(I, J, K)=N E W S I G(I, J, K P)+7 . S T E P$

$T(I, J, K)=T(I, J, K P)-(N E W S I G(I, J, K)-N E W S I G(I, J, K F)) \times O T D Z$

C $\quad F K=S I G M A(K)$ KPI $(I, J)+P T O P$

FKP $=S I G M A(K F)$ KFI $(I, \downarrow)+F T D P$

PI2=PK/FKF

C. IF ( (I.EQ. 10). AND. (J. GT. 50))

C 1 WRITE $(6,120), j, K, H E L S I G(I, J, K), Z$ ZSTEP, $T(I, J, K F), P I(I, J), F I S$,

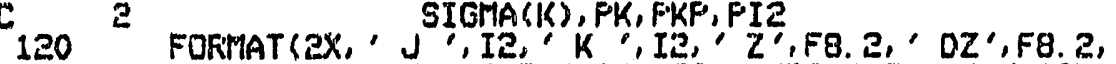

1 ' T',FO.2, 'PI',F8. 2, 'PIS',F10.2, $1,10 X$,

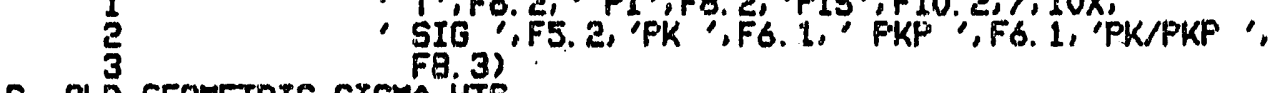

C OLD GEONETRIC SIGMA HTS

IF (K. EQ. 6) OLD=0.0

IF(K. EO. S) OLD=3.658

IF (K. ER. 4) OLD $=16.46$

IF (K. EQ. 3)OLD=31.09

IF (K. EQ. 2) $O L D=62.18$

IF (K. EQ. 1) OLD=91. 44

OLO $=O L D+S F C H T(I, J)$

c.

$\operatorname{OLSIG}(I, J, K)=O L O$
PSmPI $(I, 0)+P T O P$
C. IF(I. EQ. 99) WRITE $(6,30), I, J, K, P I S, Z$ ZTEF, F'S
30
1
FORMAT $11 X, ' I$ ', I3,' J', I3,' $K$ ', I3,
IF (TEST. EO. 1. O)GO TO 1199

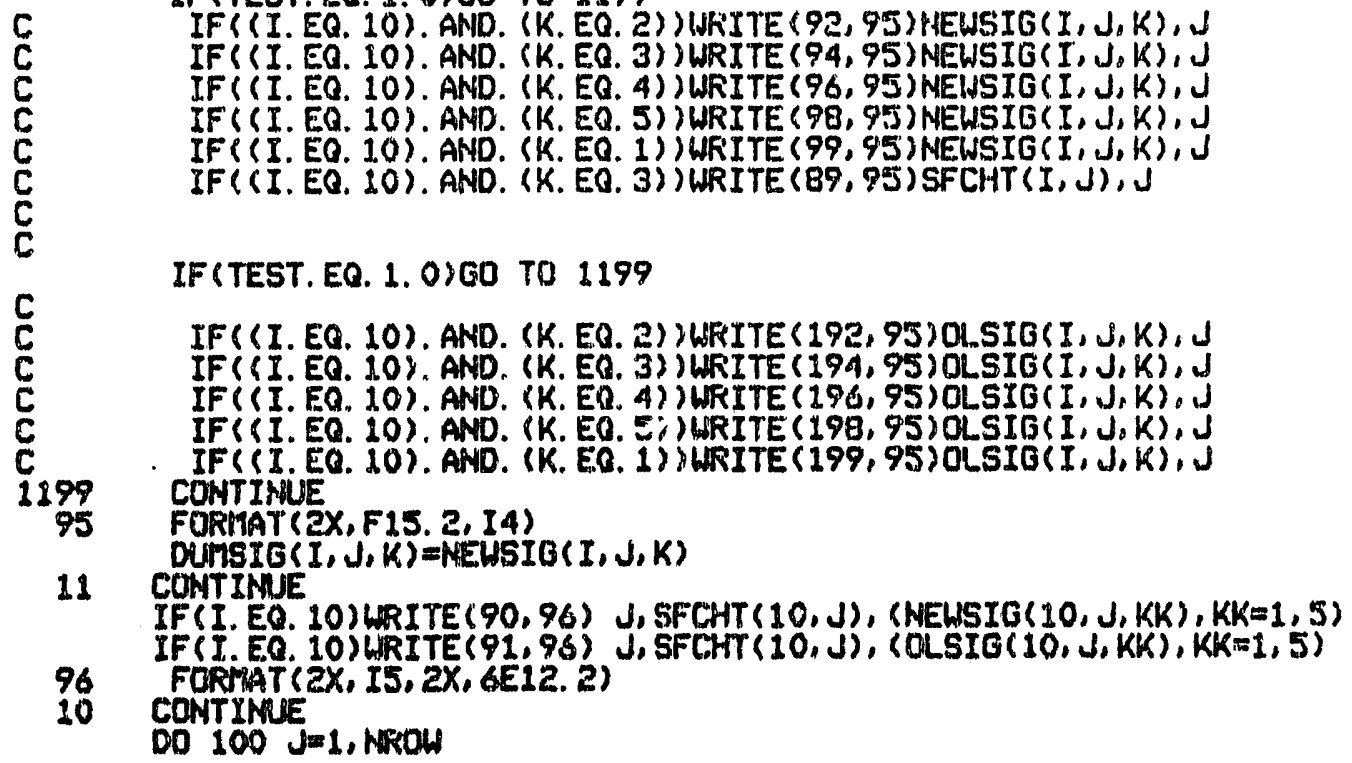




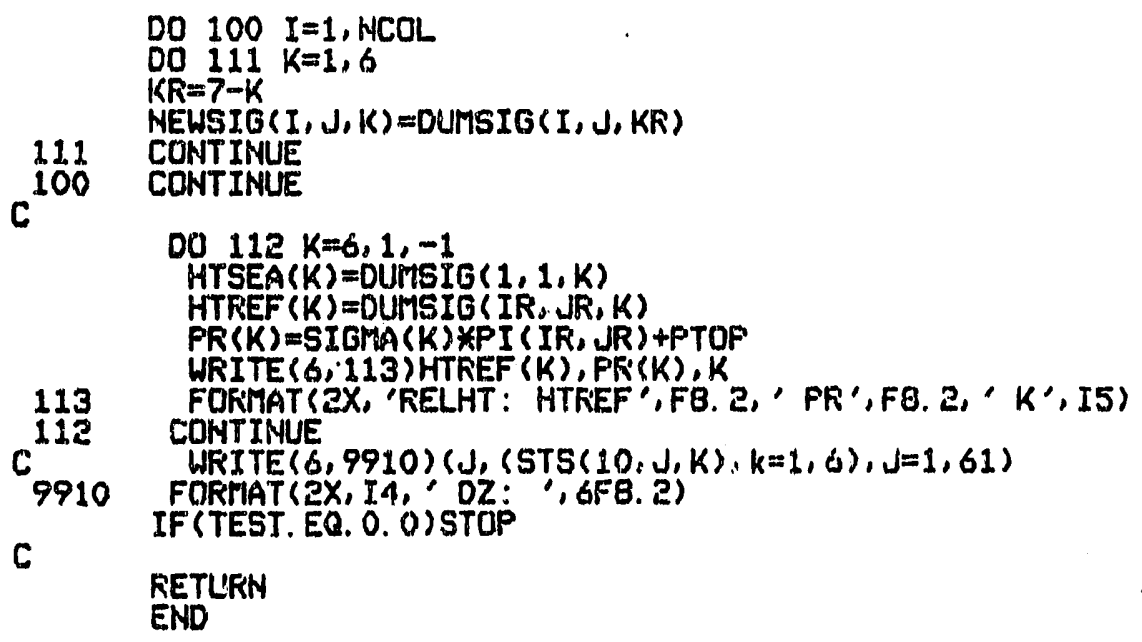

RETLRN

END 

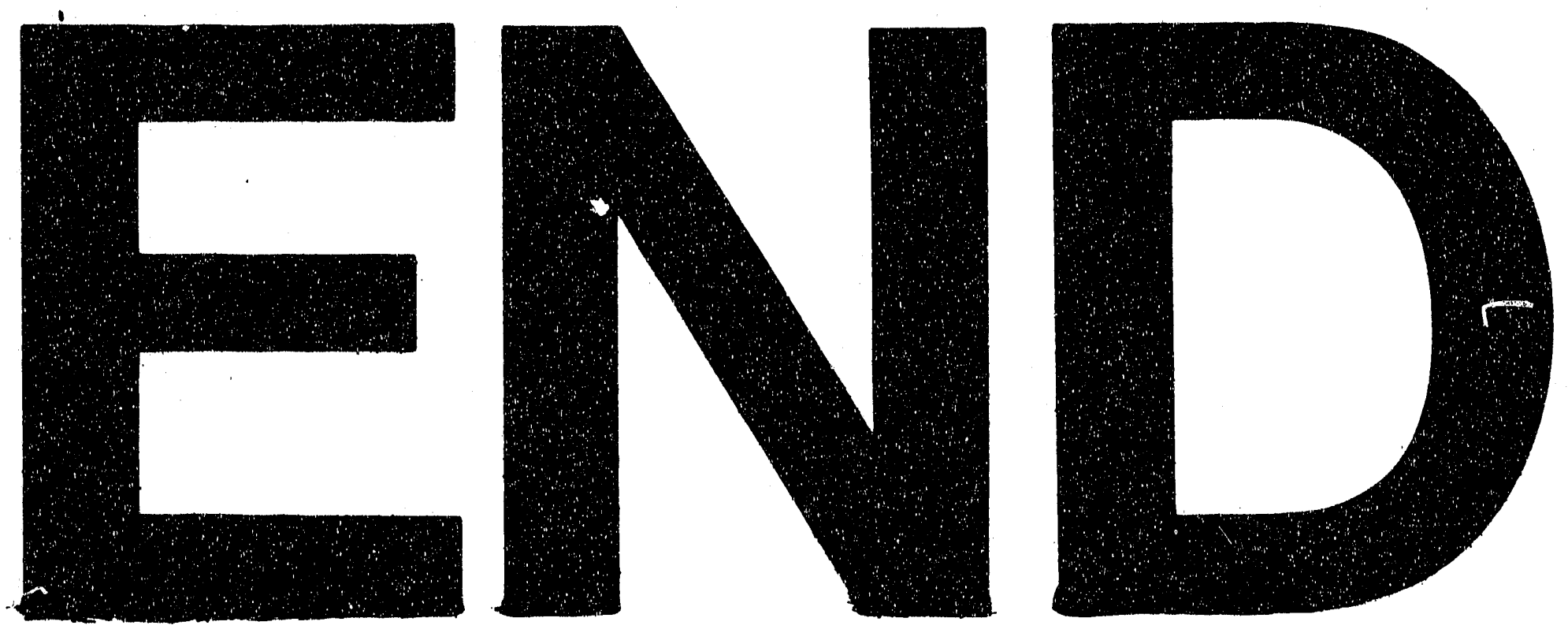
..
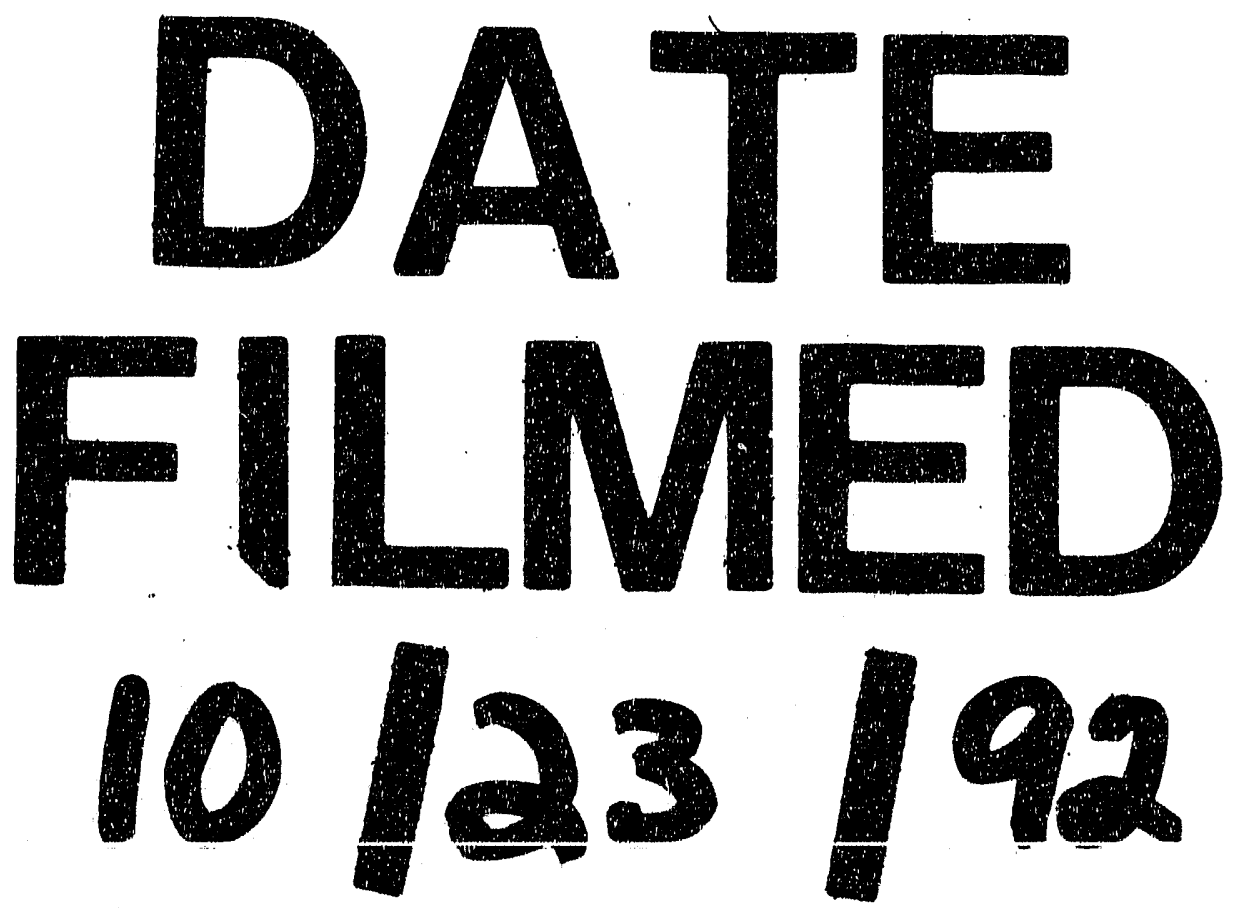
